OPEN ACCESS

Edited by:

Anders Fogh Christensen,

University of Copenhagen, Denmark

Reviewed by:

Bin Jiang,

Beijing Neurosurgical Institute, China

Krassen Nedeltchev,

Kantonsspital Aarau, Switzerland

*Correspondence:

Julian Schröder

jul.schroeder@uke.de

Specialty section:

This article was submitted to Stroke,

a section of the journal

Frontiers in Neurology

Received: 01 September 2016

Accepted: 29 December 2016

Published: 12 January 2017

Citation:

Schröder J and Thomalla G (2017) A Critical Review of Alberta Stroke

Program Early CT Score for Evaluation of Acute Stroke Imaging. Front. Neurol. 7:245.

doi: 10.3389/fneur.2016.00245

\section{A Critical Review of Alberta Stroke Program Early CT Score for Evaluation of Acute Stroke Imaging}

\author{
Julian Schröder* and Götz Thomalla \\ Department of Neurology, University Medical Center Hamburg-Eppendorf, Hamburg, Germany
}

Assessment of ischemic stroke lesions on computed tomography (CT) or MRI using the Alberta Stroke Program Early CT Score (ASPECTS) is widely used to guide acute stroke treatment. We aimed to review the current evidence on ASPECTS. Originally, the score was developed for standardized lesion assessment on non-contrast CT (NCCT). Early studies described ASPECTS as a predictor of functional outcome and symptomatic intracranial hemorrhage after iv-thrombolysis with a threshold of $\leq 7$ suggested to identify patients at high risk. Following studies rather pointed toward a linear relationship between ASPECTS and functional outcome. ASPECTS has also been applied to assess perfusion CT and diffusion-weighted MRI (DWI). Cerebral blood volume ASPECTS proved to be the best predictor of outcome, outperforming NCCT-ASPECTS in some studies. For DWI-ASPECTS varying thresholds to identify patients at risk for poor outcome were reported. ASPECTS has been used for patient selection in three of the five groundbreaking trials proving efficacy of mechanical thrombectomy published in 2015. ASPECTS values predict functional outcome after thrombectomy. Moreover, treatment effect of thrombectomy appears to depend on ASPECTS values being smaller or not present in low ASPECTS, while patients with ASPECTS 5-10 do clearly benefit from mechanical thrombectomy. However, as patients with low ASPECTS values were excluded from recent trials data on this subgroup is limited. There are several limitations to ASPECTS addressed in a growing number of studies. The score is limited to the anterior circulation, the template is unequally weighed and correlation with lesion volume depends on lesion location. Overall ASPECTS is a useful and easily applicable tool for assessment of prognosis in acute stroke treatment and to help guide acute treatment decisions regardless whether MRI or CT is used. Patients with low ASPECTS values are unlikely to achieve good outcome. However, methodological constraints of ASPECTS have to be considered, and based on present data, a clear cutoff value to define "Iow ASPECTS values" cannot be given.

Keywords: stroke, acute stroke treatment, computed tomography, magnetic resonance imaging, Alberta Stroke Program Early CT Score 


\section{INTRODUCTION}

The Alberta Stroke Program Early Computed Tomography Score (ASPECTS) is widely used in clinical practice to assess the extent of early ischemic changes on brain imaging for acute stroke treatment. ASPECTS has been applied to various imaging modalities in acute stroke imaging since its introduction in 2000. ASPECTS is a 10-point scoring system with anatomical regions distributed over the MCA territory (1).

It was designed as a robust imaging measure to predict outcome in intravenous thrombolysis. ASPECTS has drawn a lot of attention due to its use for patient exclusion in the 2015 trials demonstrating efficacy of mechanical thrombectomy (2-4).

Due to high efficacy, we will see an increase of mechanical thrombectomy over the course of the next years and with it probably an increasing use of ASPECTS in routine clinical practice, as patient stratification is key in this time-dependent treatment. There are also a rapidly growing number of scientific studies using ASPECTS in stroke research or addressing methodological questions concerning ASPECTS (please see Figure 1 for an overview of the number of studies published per year over the last 10 years). This article aims to summarize the current evidence on ASPECTS in a topical and selective review and to explain its applications in clinical practice and trials.

\section{ORIGINAL CT SCORE}

The ECASS-1 trial first established the relevance of early ischemic signs on non-contrast CT scans prior to intravenous thrombolysis (5). Von Kummer et al. showed in 1997 that patients with early ischemic changes in over one-third of the MCA territory had a lower chance of good outcome after ivrtPA (6). However, identification of patients following the $1 / 3$ of the MCA territory paradigm proved to be unreliable in clinical practice (7).

Given these limitations to the $1 / 3$ rule and the necessity to assess early ischemic changes in a reliable way, Barber et al. developed ASPECTS. The score was intended as a pragmatic, reliable,

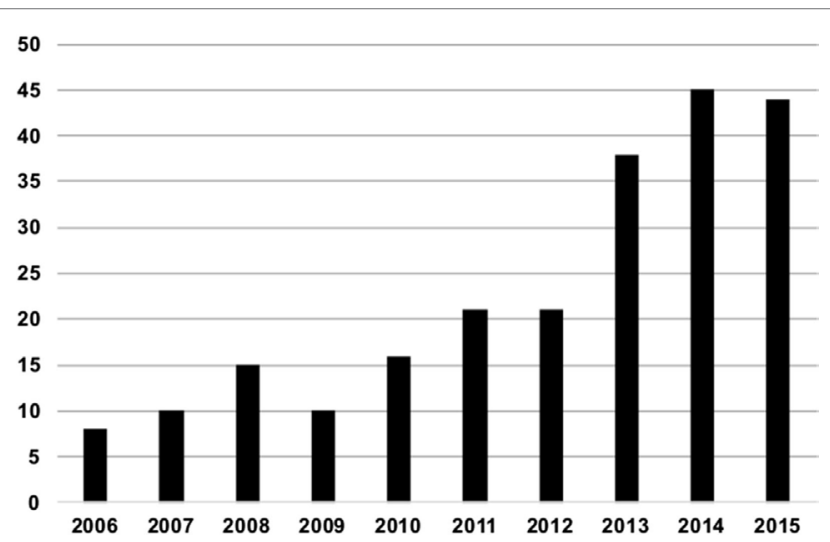

FIGURE 1 | Number of publications indexed in MedLine for the search term “Alberta Stroke Program early CT Score" per year since 2006. and easily applicable scoring template for early ischemic changes on CT (1).

The template consists of 10 anatomically defined regions, 4 for subcortical structures [caudate (C); lentiform (L); internal capsule (IC); insular ribbon (I)] and 6 for cortical structures in the MCA territory, labeled M1-M6 (1, 8) (Figure 2).

The MCA territory is assessed on all axial CT cuts in two distinct levels, the "ganglionic" and "supraganglionic" level. All axial cuts on the level of the caudate head or below are hereby allotted to the ganglionic level, all above to the supraganglionic. The caudate nucleus is part of both layers, the head belonging to the ganglionic, body, and tail to the supraganglionic level (8).

Early ischemic changes on CT were originally defined as intraparenchymal hypoattenuation (loss of gray-white matter distinction) and focal swelling. For each ASPECTS region that presents with early ischemic changes on at least two consecutive cuts, the overall score of 10 is reduced by 1 . Thus, a score of 0 would indicate infarction of all 10 regions.

Despite relatively vague definition of the individual regions interrater agreement for dichotomized ASPECTS has been described as good $(1,9,10)$ with some studies reporting moderate agreement (11-13).

\section{ASPECTS AS PREDICTOR OF STROKE OUTCOME}

The original publication proposed a cutoff of $\leq 7$ on the initial non-contrast CT (NCCT) as it predicted functional dependence in patients who underwent thrombolysis within $3 \mathrm{~h}$ from symptom onset (1).

A larger Canadian study of 936 patients treated with iv-thrombolysis in $3 \mathrm{~h}$ time window between 1999 and 2001 demonstrated a near linear inverse relationship between ASPECTS on baseline NCCT and functional outcome (14). However, in 2012, González et al. reported no significant prediction of MRS $>2$ after 6 months by ASPECTS on initial NCCT performed within $24 \mathrm{~h}$ from symptom onset in 649 patients diagnosed with ischemic stroke (15).

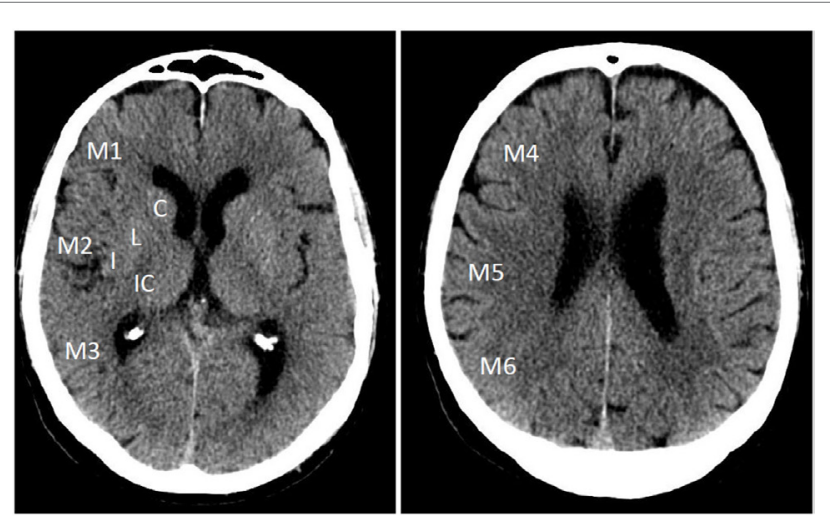

FIGURE 2 | Alberta Stroke Program Early Computed Tomography Score template on non-contrast $\mathrm{CT}$ with 10 regions distributed over the MCA territory in ganglionic and supraganglionic levels. 
For iv-thrombolysis a modification of treatment effect by ASPECTS could not be proven in 3 or $6 \mathrm{~h}$ time windows (16, 17). Still, in the NINDS rtPA Stroke Study higher ASPECTS values were associated with a greater benefit from iv treatment with rtPA (16).

\section{ASPECTS AS PREDICTOR OF SYMPTOMATIC INTRACRANIAL HEMORRHAGE AFTER THROMBOLYSIS}

Barber et al. originally described ASPECTS as a significant predictor of symptomatic intracranial hemorrhage after thrombolysis within $3 \mathrm{~h}$ from symptom onset (1). This could not be reproduced based on data from the ECASS-II or NINDS-stroke trials $(16,17)$.

In 2009, Puetz et al. published a comprehensive review focusing mainly on NCCT-ASPECTS. As isolated cortical swelling can occur in penumbra and infarct core, they proposed the removal of isolated focal swelling without hypoattenuation from the early ischemic changes relevant for scoring (18).

\section{USE OF ASPECTS WITH PERFUSION-CT AND DIFFUSION-WEIGHTED MRI}

There have been numerous publications assessing the applicability of ASPECTS to multiparametric CT and MRI. One prominent focus has been the evaluation of different CT Perfusion measures using ASPECTS.

Parsons et al. described cerebral blood volume (CBV) ASPECTS within $6 \mathrm{~h}$ from symptom onset as a more accurate predictor of irreversibly damaged tissue when compared with NCCT ASPECTS in 2007 (19). Lin et al. identified a MTT/ CBV ASPECTS mismatch of $\geq 1$ within $6 \mathrm{~h}$ as the optimal cutoff to identify a volumetric mismatch of $\geq 20 \%$ (20). MTT/CBV ASPECTS mismatch within $3 \mathrm{~h}$ from symptom onset was also highly correlated with volumetric tissue at risk in a 2011 study by Sillanpaa et al.; furthermore, CBV ASPECTS within $8 \mathrm{~h}$ from symptom onset was superior to NCCT ASPECTS in discriminating patients with favorable outcome $(21,22)$. In contrast, a large study with 824 patients from a Dutch stroke registry could not find an additional impact of CBV and MTT ASPECTS compared to only NCCT ASPECTS within $9 \mathrm{~h}$ from symptom onset when analyzed in a multivariate model. In the same study, CBV and MTT ASPECTS were significant predictors of poor clinical outcome in univariate analysis (23).

Thus, it is unclear whether CTP ASPECTS offers a clear advantage over NCCT ASPECTS, data at the present state are ambiguous. There have been reports of improved interrater reliability on CBV ASPECTS within 4.5 and $9 \mathrm{~h}$ from stroke onset compared to NCCT ASPECTS $(13,24)$.

ASPECTS has also been used to assess lesion extent on diffusion-weighted MRI (DWI), usually labeled "DWI-ASPECTS." DWI-ASPECTS within $3 \mathrm{~h}$ after symptom onset has been proven to predict functional outcome (MRS) and mortality after 3 months in patients undergoing iv-thrombolysis. As a cutoff to identify patients at risk for poor outcome DWI-ASPECTS $>6$ was proposed, though specificity was low at 33\% (25). Another study identified DWI-ASPECTS $>5$ within $3 \mathrm{~h}$ after onset as a cutoff to identify patients with good functional outcome 7 days after iv-thrombolysis (26). Based on a cohort of patients with imaging between 3 and $24 \mathrm{~h}$ after onset, Tei et al. proposed a cutoff of DWIASPECTS $>7$ to predict MRS $\geq 3$ after 3 months in 2011 (27). In all three studies, DWI-ASPECTS was an independent predictor of functional outcome. Nezu et al. found DWI-ASPECTS to be approximately 1 point lower than NCCT-ASPECTS within $3 \mathrm{~h}$ from symptom onset in 360 patients, who underwent both imaging modalities. In the same study, there was no significant difference in area under the receiver operating characteristic (ROC) curve of DWI- and NCCT-ASPECTS for prediction of MRS 0-2 at 90 days. Interrater agreement was higher for DWI-ASPECTS (28).

Overall due to the higher sensitivity of DWI (29), DWIASPECTS is more sensitive for the detection of early ischemic changes than NCCT ASPECTS (30). After endovascular therapy within $12 \mathrm{~h}$ from symptom onset DWI-ASPECTS had higher interrater agreement and according to ROC analysis outperformed NCCT ASPECTS in predicting good functional outcome at 90 days poststroke (9).

There have been multiple attempts to use ASPECTS as a surrogate marker for DWI lesion volume and a threshold of $<4$ has been proposed to identify patients with DWI volume $>100 \mathrm{ml}$ $(31,32)$. We could show that depending on lesion location estimation of DWI lesion volume by DWI-ASPECTS is unreliable (see below) (33).

\section{ASPECTS FOR USE WITH MECHANICAL THROMBECTOMY}

Identification of a clearly defined treatable lesion was highlighted as a key issue $(34,35)$ after three endovascular trials published in 2013 (36-38) failed to prove a significant additional benefit of endovascular stroke treatment over standard iv treatment. As the acute stroke setting comes along with restrictions for time consuming post processing of CT or MRI data, ASPECTS among other techniques has been proposed as a fast and easy method to identify patients suitable for endovascular reperfusion treatment.

There have been several studies suggesting an increased benefit of endovascular treatment for patients with higher ASPECTS values using various imaging modalities.

In the Penumbra Pivotal Stroke (39) trial not a single patient with ASPECTS $<5$ on the initial CT scan up to $8 \mathrm{~h}$ after symptom onset achieved a favorable outcome (MRS 0-2 after 3 months), good outcome was significantly more frequent in the ASPECTS score $>7$ group when compared to the ASPECTS score $\leq 7$ group [50 vs. $15 \%$; RR, 3.3; 95\% confidence interval (CI), 1.6-6.8; $p<0.0001]$.

A further analysis of data from trials using the Penumbra system including 249 patients again showed an increase in favorable outcome with higher ASPECTS values (40). Symptomatic intracranial hemorrhage was more frequent in patients with low ASPECTS scores on initial CT scans. Furthermore, patients with ASPECTS 0-4 had significantly worse outcome than patients with ASPECTS 5-10 and did not benefit from faster treatment, 
thus suggesting a cutoff ASPECTS $\leq 4$ to identify patients with poor response to intravascular treatment (40).

In a study of 51 patients undergoing aspiration thrombectomy with a median onset to recanalization time of 292 (IQR 246-357) min, patients with good outcome (MRS 0-2) had significantly higher CBV ASPECTS (CBV ASPECTS 8 vs. 6, $p=0.0007$ ), CBV ASPECTS $>7$ was identified as optimal cutoff with a positive predictive value of $65 \%$ (41). This was reproduced by Lum et al. in a collective of 46 patients within $6 \mathrm{~h}$ from symptom onset (42).

Soize et al. reported an independent prediction of outcome and of symptomatic intracranial hemorrhage by DWI-ASPECTS in 59 patients after mechanical thrombectomy (mean time from symptom onset to recanalization $296 \mathrm{~min}$ ) (43). Inoue et al. identified DWI-ASPECTS $\geq 5$ as the optimal predictor of favorable outcome after 90 days following intra-arterial treatment in a collective of 210 patients [median time from onset to MRI 105 (IQR 75-178) min] (44).

In the IMS-III trial (656 subjects randomized), patients with ASPECTS 8-10 on initial NCCT up to $3 \mathrm{~h}$ after symptom onset were almost twice as likely (relative risk, 1.8; 99\% CI, 1.4-2.4) to achieve a favorable outcome. However, there was no significant treatment by ASPECTS interaction (45).

\section{ASPECTS IN THE LARGE STENT-TRIEVER THROMBECTOMY TRIALS}

In 2015, five randomized-controlled trials demonstrated a strong positive effect of mechanical thrombectomy using stent-triever devices on patient outcome when compared with standard iv treatment alone. Most of these trials used NCCT-ASPECTS for patient selection based on the experience of the studies cited above.

The first new generation thrombectomy trial published, MR CLEAN did not use an ASPECTS threshold for patient exclusion. Patients were included up to $6 \mathrm{~h}$ after symptom onset. There was a consistent additional effect of intra-arterial treatment over all ASPECTS ranges analyzed (0-4, 5-7, 8-10). Intra-arterial treatment caused no increase of symptomatic intracranial hemorrhage in any of the ASPECTS groups compared iv treatment only. However, only 30 patients with ASPECTS 0-4 were analyzed and only one of those achieved MRS $2(46,47)$.

Based on the findings of Inoue et al. (44), the SWIFT-PRIME study used NCCT- or DWI-ASPECTS $\leq 5$ within $6 \mathrm{~h}$ after symptom onset as an exclusion threshold. There was no difference in outcome between patients with ASPECTS 6-7 and 8-10 (4). Investigators in the ESCAPE study also applied an ASPECTS threshold of $\leq 5$ up to $12 \mathrm{~h}$ after symptom onset to exclude patients. Again, there was no heterogeneity of effect between patients with ASPECTS 6-7 and 8-10 (2).

The only study to use DWI-ASPECTS and NCCT-ASPECTS in a time window up to $8 \mathrm{~h}$ after symptom onset was REVASCAT. To account for the different sensitivities of DWI and NCCTimaging a threshold of $<7$ was applied to CT and $<6$ to DWI for patient exclusion. The difference of 1 point between DWIand NCCT-ASPECTS was chosen based on earlier findings by
Nezu et al. (28). There was no significant difference in outcome for patients with ASPECTS $\leq 7$ and above (3). In EXTEND-IA, patient selection was not based on ASPECTS but on volumetric infarct core to perfusion lesion mismatch (48).

A recent meta-analysis performed a central reading of all pretreatment scans from the five thrombectomy trials and found a clear benefit of thrombectomy in patients with ASPECTS > 5 (49). Of note, in the pooled data, median ASPECTS was 9 for both the treatment (IQR 7-10) and control (IQR 8-10) groups. Treatment effect was analyzed for three ASPECTS strata: $0-5,6-8$, and 9-10. While there was a strong and consistent treatment effect for both ASPECTS 6-8 and 9-10 with an adjusted odds ratio of OR 2.36 (95\% CI 1.68-3.26) and 2.66 (1.61-4.40), no clear benefit was observed for 121 patients with ASPECT 0-5 with an OR of 1.24 $(0.62-2.42)$. Figure 3 illustrates the odds ratios for the different ASPECTS subgroups.

\section{METHODOLOGICAL ISSUES AND LIMITATIONS OF ASPECTS}

Despite its broad application ASPECTS has limitations. First of all, the original ASPECTS score is limited to the anterior circulation only (1). Second, ASPECTS shows an unequal weighing of brain regions, as first described in 2006 by Phan et al. (50). The template is based on anatomical structures, and thus, the individual regions cover different amounts of brain tissue. Additionally, the exact extent of each region or how much damaged tissue is required to render a region affected has never been defined (1).

In a study of 496 patients, we could show that correlation of ASPECTS with DWI lesion volume varied considerably depending on lesion location (33). Figure 4 shows the distribution of lesion volumes for ASPECTS values $>4$. Two patients with the same ASPECTS score do not necessarily have similar lesion volumes. As lesion volume is a strong predictor of functional outcome (51-53), the template's unequal weighing could compromise clinical decisions. If decision making is based solely on an ASPECTS threshold this might lead to unjustified exclusion

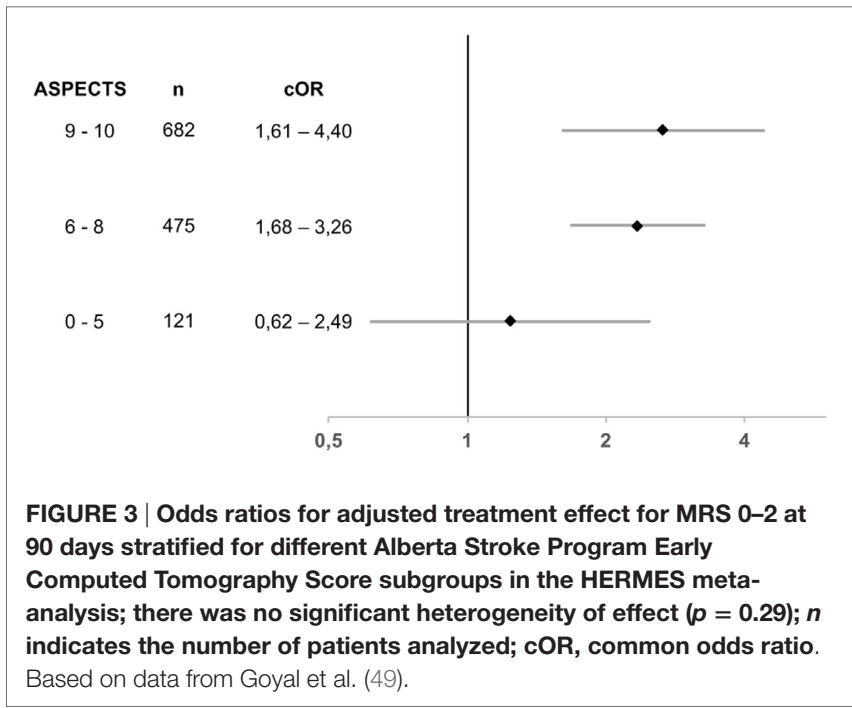




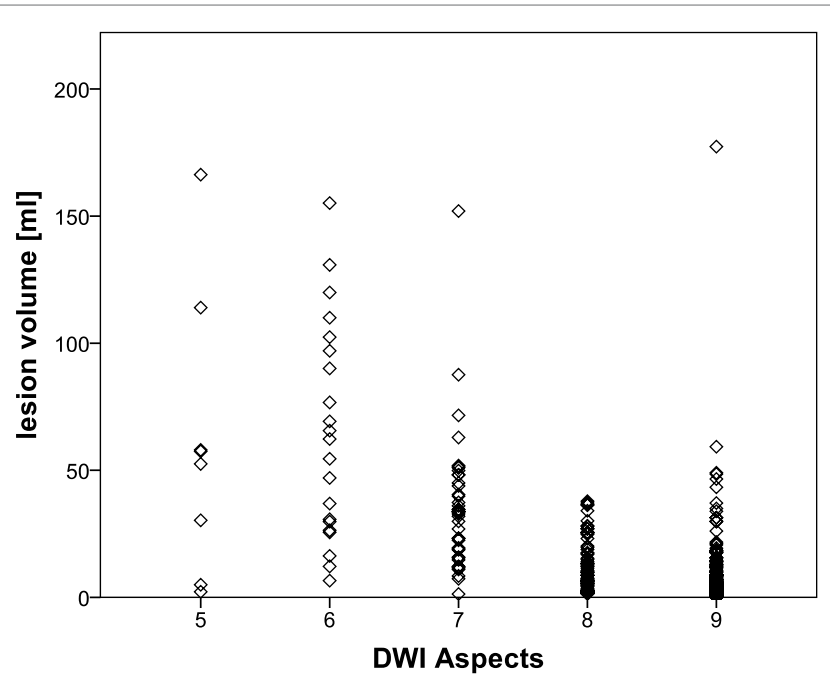

FIGURE 4 | Distribution of lesion volumes in patients with diffusionweighted MRI (DWI)-Alberta Stroke Program Early Computed Tomography Score (ASPECTS) $\geq 5$, these patients were shown to benefit from mechanical thrombectomy in the recent HERMES meta-analysis (49). Lesion volumes varied considerably in patients with the same DWI ASPECTS. Based on data from Schröder et al. (33).

of patients from clinical trials or even treatment when lesion location is not considered.

Depending on analyzed sample, treatment, and imaging modality applied, various cutoffs to identify patients at risk of poor outcome have been suggested (1, 14, 20, 25-27, 47). Furthermore, large studies suggested a linear relationship or even no significant outcome prediction by ASPECTS at all $(14,15)$. Thus, recommendation of one single threshold to identify patients with poor outcome based on the available data seems hardly justifiable.

Another issue confined to the widely used NCCT ASPECTS is the poor sensitivity in the early period after stroke (29).

\section{CONCLUSION}

ASPECTS is a useful and easily applicable tool for standardized evaluation of the extent of acute ischemic lesions that may help in the assessment of prognosis in acute stroke treatment regardless

\section{REFERENCES}

1. Barber PA, Demchuk AM, Zhang J, Buchan AM, Study A. Validity and reliability of a quantitative computed tomography score in predicting outcome of hyperacute stroke before thrombolytic therapy. Lancet (2000) 355:1670-4. doi:10.1016/S0140-6736(00)02237-6

2. Goyal M, Demchuk AM, Menon BK, Eesa M, Rempel JL, Thornton J, et al. Randomized assessment of rapid endovascular treatment of ischemic stroke. N Engl J Med (2015) 372(11):1019-30. doi:10.1056/NEJMoa1414905

3. Jovin TG, Chamorro A, Cobo E, de Miquel MA, Molina CA, Rovira A, et al. Thrombectomy within 8 hours after symptom onset in ischemic stroke. N Engl J Med (2015) 372(24):1-11. doi:10.1056/NEJMoa1503780

4. Saver JL, Goyal M, Bonafe A, Diener H-C, Levy EI, Pereira VM, et al. Stentretriever thrombectomy after intravenous t-PA vs. t-PA alone in stroke. $N$ Engl J Med (2015) 372(24):2285-95. doi:10.1056/NEJMoa1415061 whether MRI or CT is used. Patients with low ASPECTS values are unlikely to achieve good outcome. However, based on present data, a clear cutoff value to define "low ASPECTS values" cannot be given.

A clear advantage of CT perfusion ASPECTS over NCCT ASPECTS has not been established, both could be shown to predict poor functional outcome as assessed by the MRS after 90 days. CBV ASPECTS may offer slightly improved interrater reliability.

Due to DWI's high sensitivity, a key issue of DWI-ASPECTS is the definition how much lesioned tissue is required for a region to be counted as affected. Formal instructions are lacking. This could explain at least part of the variance in the proposed cutoff values. There are contradicting reports comparing the performances of DWI-ASPECTS and NCCT-ASPECTS for outcome prediction. Interrater agreement was improved for DWI-ASPECTS compared to NCCT-ASPECTS.

ASPECTS may further helpful in guiding patient selection for enrollment in clinical trials as well as for reperfusion treatment. For mechanical thrombectomy, a clear benefit over iv treatment alone has been proven for patients with NCCT ASPECTS 6-10, while for ASPECTS values 0-5 treatment effect is not clear.

However, when applying ASPECTS cutoffs methodological limitations have to be considered resulting from the unequal weighing of different brain regions by ASPECTS. As a consequence, stroke lesions with the same ASPECTS rating may have quite different lesion extent depending on their location. Thus, we do not recommend to stick to strict NCCT- or DWI-ASPECTS values for exclusion of patients from treatment but rather consider ASPECTS as a helpful of diagnostic tools that should be looked at in the broader perspective including other imaging and clinical features.

\section{AUTHOR CONTRIBUTIONS}

Both JS and GT made substantial contributions to the conception, the acquisition, analysis, and interpretation of data for the work; drafted the work and/or revised it critically for important intellectual content; approved the final version to be published; and agreed to be accountable for all aspects of the work in ensuring that questions related to the accuracy or integrity of any part of the work are appropriately investigated and resolved.

5. Hacke W, Kaste M, Fieschi C, Toni D, Lesaffre E, von Kummer R, et al intravenous thrombolysis with recombinant tissue plasminogen activator for acute hemispheric stroke. JAMA (1995) 274(13):1017-25. doi:10.1001/ jama.1995.03530130023023

6. von Kummer R, Allen KL, Holle R, Bozzao L, Bastianello S, Manelfe C, et al. Acute stroke: usefulness of early CT findings before thrombolytic therapy. Radiology (1997) 205(2):327-33. doi:10.1148/radiology.205.2. 9356611

7. Grotta JC, Chiu D, Lu M, Patel S, Levine SR, Tilley BC, et al. Agreement and variability in the interpretation of early CT changes in stroke patients qualifying for intravenous rtPA therapy. Stroke (1999) 30(8):1528-33. doi:10.1161/ 01.STR.30.8.1528

8. Modi J, Menon B, Goyal M. Alberta Stroke Program Early CT Score (ASPECTS). [Internet] [cited 25 July 2016]. Available from: http://www.ASPECTSin Stroke.Com 
9. McTaggart RA, Jovin TG, Lansberg MG, Mlynash M, Jayaraman MV, Choudhri OA, et al. Alberta stroke program early computed tomographic scoring performance in a series of patients undergoing computed tomography and MRI: reader agreement, modality agreement, and outcome prediction. Stroke (2015) 46(2):407-12. doi:10.1161/STROKEAHA.114.006564

10. Pexman JHW, Barber PA, Hill MD, Sevick RJ, Demchuk AM, Hudon ME, et al. Use of the Alberta stroke program early CT score (ASPECTS) for assessing CT scans in patients with acute stroke. Am J Neuroradiol (2001) 22(8):1534-42.

11. Gupta AC, Schaefer PW, Chaudhry ZA, Leslie-Mazwi TM, Chandra RV, González RG, et al. Interobserver reliability of baseline noncontrast CT Alberta stroke program early CT score for intra-arterial stroke treatment selection. AJNR Am JNeuroradiol (2012) 33(6):1046-9. doi:10.3174/ajnr. A2942

12. Mak HKF, Yau KKW, Khong PL, Ching ASC, Cheng PW, Au-Yeung PKM, et al. Hypodensity of $>1 / 3$ middle cerebral artery territory versus Alberta sroke programme early CT score (ASPECTS): comparison of two methods of quantitative evaluation of early CT changes in hyperacute ischemic stroke in the community setting. Stroke (2003) 34(5):1194-6. doi:10.1161/01.STR. 0000069162.64966 .71

13. van Seeters T, Biessels GJ, Niesten JM, van der Schaaf IC, Dankbaar JW, Horsch $\mathrm{AD}$, et al. Reliability of visual assessment of non-contrast CT, CT angiography source images and CT perfusion in patients with suspected ischemic stroke. PLoS One (2013) 8(10):e75615. doi:10.1371/journal.pone.0075615

14. Hill MD, Buchan AM; Canadian Alteplase for Stroke Effectiveness Study (CASES) Investigators. Thrombolysis for acute ischemic stroke: results of the Canadian Alteplase for Stroke Effectiveness Study. CMAJ (2005) 172(10):1307-12. doi:10.1503/cmaj.1041561

15. González RG, Lev MH, Goldmacher GV, Smith WS, Payabvash S, Harris GJ, et al. Improved outcome prediction using CT angiography in addition to standard ischemic stroke assessment: results from the STOPStroke study. PLoS One (2012) 7(1):e30352. doi:10.1371/journal.pone.0030352

16. Demchuk AM, Hill MD, Barber PA, Silver B, Patel SC, Levine SR, et al. Importance of early ischemic computed tomography changes using ASPECTS in NINDS rtPA stroke study. Stroke (2005) 36(10):2110-5. doi:10.1161/01.STR.0000181116.15426.58

17. Dzialowski I, Hill MD, Coutts SB, Demchuk AM, Kent DM, Wunderlich $\mathrm{O}$, et al. Extent of early ischemic changes on computed tomography (CT) before thrombolysis: prognostic value of the Alberta stroke program early CT score in ECASS II. Stroke (2006) 37(4):973-8. doi:10.1161/ 01.STR.0000206215.62441.56

18. Puetz V, Dzialowski I, Hill MD, Demchuk AM. The Alberta stroke program early CT score in clinical practice: what have we learned? Int J Stroke (2009) 4(5):354-64. doi:10.1111/j.1747-4949.2009.00337.x

19. Parsons MW, Pepper EM, Bateman GA, Wang Y, Levi CR. Identification of the penumbra and infarct core on hyperacute noncontrast and perfusion CT. Neurology (2007) 68(10):730-6. doi:10.1212/01.wnl.0000256366.86353.ff

20. Lin K, Rapalino O, Lee B, Do KG, Sussmann AR, Law M, et al. Correlation of volumetric mismatch and mismatch of Alberta stroke program early CT scores on CT perfusion maps. Neuroradiology (2009) 51(1):17-23. doi:10.1007/ s00234-008-0454-y

21. Sillanpaa N, Saarinen JT, Rusanen H, Hakomaki J, Lahteela A, Numminen $\mathrm{H}$, et al. CT perfusion ASPECTS in the evaluation of acute ischemic stroke: thrombolytic therapy perspective. Cerebrovasc Dis Extra (2011) 1(1):6-16. doi: $10.1159 / 000324324$

22. Padroni M, Bernardoni A, Tamborino C, Roversi G, Borrelli M, Saletti A, et al. Cerebral blood volume ASPECTS is the best predictor of clinical outcome in acute ischemic stroke: a retrospective, combined semi-quantitative and quantitative assessment. PLoS One (2016) 11(1):e0147910. doi:10.1371/ journal.pone.0147910

23. Van Seeters T, Biessels GJ, Kappelle LJ, Van Der Schaaf IC, Dankbaar JW, Horsch $\mathrm{AD}$, et al. The prognostic value of CT angiography and CT perfusion in acute ischemic stroke. Cerebrovasc Dis (2015) 40(5-6):258-69. doi: $10.1159 / 000441088$

24. Finlayson O, John V, Yeung R, Dowlatshahi D, Howard P, Zhang L, et al. Interobserver agreement of ASPECT score distribution for noncontrast CT, CT angiography, and CT perfusion in acute stroke. Stroke (2013) 44(1):234-6. doi:10.1161/STROKEAHA.112.665208

25. Nezu T, Koga M, Kimura K, Shiokawa Y, Nakagawara J, Furui E, et al. Pretreatment ASPECTS on DWI predicts 3-month outcome following rt-PA:
SAMURAI rt-PA registry. Neurology (2010) 75(6):555-61. doi:10.1212/ WNL.0b013e3181eccf78

26. Kimura K, Iguchi Y, Shibazaki K, Terasawa Y, Inoue T, Uemura J, et al. Large ischemic lesions on diffusion-weighted imaging done before intravenous tissue plasminogen activator thrombolysis predicts a poor outcome in patients with acute stroke. Stroke (2008) 39(8):2388-91. doi:10.1161/ STROKEAHA.107.510917

27. Tei H, Uchiyama S, Usui T, Ohara K. Diffusion-weighted ASPECTS as an independent marker for predicting functional outcome. J Neurol (2011) 258(4):559-65. doi:10.1007/s00415-010-5787-x

28. Nezu T, Koga M, Nakagawara J, Shiokawa Y, Yamagami H, Furui E, et al. Early ischemic change on CT versus diffusion-weighted imaging for patients with stroke receiving intravenous recombinant tissue-type plasminogen activator therapy: stroke acute management with urgent risk-factor assessment and improvement (SAMURAI) rt-PA registry. Stroke (2011) 42(8):2196-200. doi:10.1161/STROKEAHA.111.614404

29. Chalela JA, Kidwell CS, Nentwich LM, Luby M, Butman JA, Demchuk AM, et al. Magnetic resonance imaging and computed tomography in emergency assessment of patients with suspected acute stroke: a prospective comparison. Lancet (2007) 369(9558):293-8. doi:10.1016/S0140-6736(07)60151-2

30. Mitomi M, Kimura K, Aoki J, Iguchi Y. Comparison of CT and DWI findings in ischemic stroke patients within 3 hours of onset. J Stroke Cerebrovasc Dis (2014) 23(1):37-42. doi:10.1016/j.jstrokecerebrovasdis. 2012.08.014

31. de Margerie-Mellon C, Turc G, Tisserand M, Naggara O, Calvet D, Legrand L, et al. Can DWI-ASPECTS substitute for lesion volume in acute stroke? Stroke (2013) 44(12):3565-7. doi:10.1161/STROKEAHA.113.003047

32. Lin K, Lee SA, Zink WE. What ASPECTS value best predicts the $100-\mathrm{mL}$ threshold on diffusion weighted imaging? Study of 150 patients with middle cerebral artery stroke. J Neuroimaging (2011) 21(3):229-31. doi:10.1111/j.1552-6569.2010.00487.x

33. Schröder J, Cheng B, Ebinger M, Köhrmann M, Wu O, Kang DW, et al. Validity of acute stroke lesion volume estimation by diffusion-weighted imaging-Alberta stroke program early computed tomographic score depends on lesion location in 496 patients with middle cerebral artery stroke. Stroke (2014) 45(12):3583-8. doi:10.1161/STROKEAHA.114.006694

34. Goyal M, Almekhlafi M, Menon B, Hill M, Fargen K, Parsons M, et al. Challenges of acute endovascular stroke trials. Stroke (2014) 45(10):3116-22. doi:10.1161/STROKEAHA.114.006288

35. Campbell BCV, Donnan GA, Lees KR, Hacke W, Khatri P, Hill MD, et al. Endovascular stent thrombectomy: the new standard of care for large vessel ischaemic stroke. Lancet Neurol (2015) 14(8):846-54. doi:10.1016/ S1474-4422(15)00140-4

36. Broderick JP, Palesch YY, Demchuk AM, Yeatts SD, Khatri P, Hill MD, et al Endovascular therapy after intravenous t-PA versus t-PA alone for stroke. N Engl J Med (2013) 368(10):893-903. doi:10.1056/NEJMoa1214300

37. Ciccone A, Valvassori L, Nichelatti M, Sgoifo A, Ponzio M, Sterzi R, et al. Endovascular treatment for acute ischemic stroke. N Engl J Med (2013) 368(10):904-13. doi:10.1056/NEJMoa1213701

38. Kidwell CS, Jahan R, Gornbein J, Alger JR, Nenov V, Ajani Z, et al. A trial of imaging selection and endovascular treatment for ischemic stroke. $N$ Engl J Med (2013) 368(10):914-23. doi:10.1056/NEJMoa1212793

39. Penumbra Pivotal Stroke Trial Investigators. The penumbra pivotal stroke trial: safety and effectiveness of a new generation of mechanical devices for clot removal in intracranial large vessel occlusive disease. Stroke (2009) 40(8):2761-8. doi:10.1161/STROKEAHA.108.544957

40. Yoo AJ, Zaidat OO, Chaudhry ZA, Berkhemer OA, Gilberto Gonzalez R, Goyal $\mathrm{M}$, et al. Impact of pretreatment noncontrast CT Alberta stroke program early ct score on clinical outcome after intra arterial stroke therapy. Stroke (2014) 45(3):746-51. doi:10.1161/STROKEAHA.113.004260

41. Psychogios MN, Schramm P, Frölich AM, Kallenberg K, Wasser K, Reinhardt L, et al. Alberta stroke program early CT scale evaluation of multimodal computed tomography in predicting clinical outcomes of stroke patients treated with aspiration thrombectomy. Stroke (2013) 44(8):2188-93. doi:10.1161/ STROKEAHA.113.001068

42. Lum C, Ahmed ME, Patro S, Thornhill R, Hogan M, Iancu D, et al. Computed tomographic angiography and cerebral blood volume can predict final infarct volume and outcome after recanalization. Stroke (2014) 45(9):2683-8. doi:10.1161/STROKEAHA.114.006163 
43. Soize S, Barbe C, Kadziolka K, Estrade L, Serre I, Pierot L. Predictive factors of outcome and hemorrhage after acute ischemic stroke treated by mechanical thrombectomy with a stent-retriever. Neuroradiology (2013) 55(8):977-87. doi:10.1007/s00234-013-1191-4

44. Inoue M, Olivot JM, Labreuche J, Mlynash M, Tai W, Albucher JF, et al. Impact of diffusion-weighted imaging Alberta stroke program early computed tomography score on the success of endovascular reperfusion therapy. Stroke (2014) 45(7):1992-8. doi:10.1161/STROKEAHA.114.005084

45. Hill MD, Demchuk AM, Goyal M, Jovin TG, Foster LD, Tomsick TA, et al. Alberta stroke program early computed tomography score to select patients for endovascular treatment interventional management of stroke (IMS)-III trial. Stroke (2014) 45(2):444-9. doi:10.1161/STROKEAHA.113.003580

46. Berkhemer OA, Fransen PSS, Beumer D, van den Berg LA, Lingsma HF, Yoo AJ, et al. A randomized trial of intraarterial treatment for acute ischemic stroke. N Engl J Med (2015) 372(1):11-20. doi:10.1056/NEJMoa1411587

47. Yoo AJ, Berkhemer OA, Fransen PSS, van den Berg LA, Beumer D, Lingsma $\mathrm{HF}$, et al. Effect of baseline Alberta stroke program early CT score on safety and efficacy of intra-arterial treatment: a subgroup analysis of a randomised phase 3 trial (MR CLEAN). Lancet Neurol (2016) 15(7):685-94. doi:10.1016/ S1474-4422(16)00124-1

48. Campbell BCV, Mitchell PJ, Kleinig TJ, Dewey HM, Churilov L, Yassi N, et al. Endovascular therapy for ischemic stroke with perfusion-imaging selection. N Engl J Med (2015) 372(11):1009-18. doi:10.1056/NEJMoa1414792

49. Goyal M, Menon BK, van Zwam WH, Dippel DWJ, Mitchell PJ, Demchuk AM, et al. Endovascular thrombectomy after large-vessel ischaemic stroke: a meta-analysis of individual patient data from five randomised trials. Lancet (2016) 387(10029):1723-31. doi:10.1016/S0140-6736(16)00163-X
50. Phan TG, Donnan GA, Koga M, Mitchell LA, Molan M, Fitt G, et al. The ASPECTS template is weighted in favor of the striatocapsular region. Neuroimage (2006) 31(2):477-81. doi:10.1016/j.neuroimage.2005.12.059

51. Yoo AJ, Chaudhry ZA, Nogueira RG, Lev MH, Schaefer PW, Schwamm LH, et al. Infarct volume is a pivotal biomarker after intra-arterial stroke therapy. Stroke (2012) 43(5):1323-30. doi:10.1161/STROKEAHA.111.639401

52. Zaidi SF, Aghaebrahim A, Urra X, Jumaa MA, Jankowitz B, Hammer M, et al. Final infarct volume is a stronger predictor of outcome than recanalization in patients with proximal middle cerebral artery occlusion treated with endovascular therapy. Stroke (2012) 43(12):3238-44. doi:10.1161/ STROKEAHA.112.671594

53. Al-Ajlan FS, Goyal M, Demchuk AM, Minhas P, Sabiq F, Assis Z, et al. Intra-arterial therapy and post-treatment infarct volumes: insights from the ESCAPE randomized controlled trial. Stroke (2016) 47(3):777-81. doi:10.1161/STROKEAHA.115.012424

Conflict of Interest Statement: The authors declare that the research was conducted in the absence of any commercial or financial relationships that could be construed as a potential conflict of interest.

Copyright (C) 2017 Schröder and Thomalla. This is an open-access article distributed under the terms of the Creative Commons Attribution License (CC BY). The use, distribution or reproduction in other forums is permitted, provided the original author(s) or licensor are credited and that the original publication in this journal is cited, in accordance with accepted academic practice. No use, distribution or reproduction is permitted which does not comply with these terms. 